Kennesaw State University

DigitalCommons@Kennesaw State University

Faculty Publications

$1-7-2014$

\title{
Medical-Surgical Nurses' Perceived Self- Confidence and Leadership Abilities as First Responders in Acute Patient Deterioration Events
}

\author{
Patricia L. Hart \\ Kennesaw State University, phart@kennesaw.edu \\ LeeAnna Spiva \\ WellStar Development Center \\ Pamela Baio \\ WellStar Kennestone Hospital \\ Barbara Huff \\ WellStar Paulding Hospital
}

Follow this and additional works at: https://digitalcommons.kennesaw.edu/facpubs

Part of the Nursing Commons

\section{Recommended Citation}

Hart, P. L., Spiva, L., Baio, P., Huff, B., Whitfield, D., Law, T., ... \& Mendoza, I. G. (2014). Medical-surgical nurses' perceived self-confidence and leadership abilities as first responders in acute patient deterioration events. Journal of clinical nursing, 23(19-20), 2769-2778. 


\section{JCN Journal of Clinical Nursing}

\section{MEDICAL-SURGICAL NURSES' PERCEIVED SELF- CONFIDENCE AND LEADERSHIP ABILITIES AS FIRST RESPONDERS IN ACUTE PATIENT DETERIORATION EVENTS}

\begin{tabular}{|r|l|}
\hline Journal: & Journal of Clinical Nursing \\
\hline Manuscript ID: & JCN-2013-0279.R2 \\
\hline Manuscript Type: & Original Article \\
\hline Keywords: & $\begin{array}{l}\text { Acute Care, Emergency, Hospital Patients, Professional Development, } \\
\text { Leadership }\end{array}$ \\
\hline \multicolumn{2}{|l}{} \\
\hline
\end{tabular}

SCHOLARONE ${ }^{m}$

Manuscripts 


\begin{abstract}
Objective: To explore and understand medical-surgical nurses' perceived self-confidence and leadership abilities as first responders in recognizing and responding to clinical deterioration prior to the arrival of an emergency response team.

Background: Patients are admitted to hospitals with multiple, complex health issues who are more likely to experience clinical deterioration. The majority of clinical deterioration events occur on medical-surgical units and medical-surgical nurses are frequently the first healthcare professionals to identify signs and symptoms of clinical deterioration and initiate life-saving interventions.
\end{abstract}

Design: A prospective, cross sectional, descriptive quantitative design using a survey method was used.

Methods: Nurses were recruited from an integrated healthcare system located in the southeast United States. Nurses completed a demographic, a self-confidence, and a leadership ability questionnaire.

Results: One hundred and forty eight nurses participated in the study. Nurses felt moderately self-confident in recognizing, assessing, and intervening during clinical deterioration events. In addition, nurses felt moderately comfortable performing leadership skills prior to the arrival of an emergency response team. A significant, positive relationship was found between perceived self-confidence and leadership abilities. Age and certification status were significant predictors of nurses' leadership ability.

Conclusion: Although nurses felt moderately self-confident and comfortable with executing leadership abilities, improvement is needed to ensure nurses are competent in recognizing patients' deterioration cues and making sound decisions in taking appropriate, timely actions to 
rescue patients. Further strategies need to be developed to increase nurses'self-confidence and execution of leadership abilities in handling deterioration events for positive patient outcomes. Relevance to clinical practice: Educational provisions should focus on various clinical deterioration events to build nurses' self-confidence and leadership abilities in handling clinical deterioration. Nurses should obtain national certification to increase their knowledge and clinical reasoning skills.

Keywords: acute patient deterioration, medical-surgical nurses, self-confidence, leadership abilities

\section{Abstract word count: 283 \\ Manuscript word count: 4,163}

\section{What does this paper contribute to the wider global clinical community?}

- Patients are admitted to hospitals with multiple, complex health issues who are more likely to experience clinical deterioration.

- Nurses were only moderately self-confident in recognizing, assessing, and intervening during clinical deterioration events, and were only moderately comfortable in performing leadership skills prior to the arrival of an emergency response team.

- To ensure best outcomes for patients, healthcare organizations need to conduct baseline assessments of nurses to identify areas needing improvement in assessment skills, recognition, knowledge, leadership abilities, and self-confidence in clinical deterioration events on a routine basis. 


\section{MEDICAL-SURGICAL NURSES’ PERCEIVED SELF-CONFIDENCE AND LEADERSHIP ABILITIES AS FIRST RESPONDERS IN ACUTE PATIENT DETERIORATION EVENTS}

Patients enter healthcare organizations with the trust and assumption that nurses are trained and competent to detect early warning signs of acute clinical deterioration and have the self-confidence and leadership abilities to respond and intervene with appropriate actions. Nurses perform patient care within a very complex and ever changing practice environment that at times can be unpredictable requiring the effective use of critical thinking skills to make quick, appropriate clinical decisions in crisis situations. Patients are admitted to healthcare organizations with multiple, complex health issues who are more likely to experience an acute patient deterioration (APD) event during their hospitalization (Bright et al. 2004). Acute deterioration can happen at any time during patients' hospitalization. Patients are especially vulnerable following emergent admissions, after surgery, or during recovery from critical illness (Beaumont et al. 2008). The majority of APD events occur on medical-surgical nursing units (Cohn et al. 2004, Peters \& Boyde 2007) and medical-surgical nurses are frequently the first healthcare professionals to identify signs and symptoms of clinical deterioration and initiate lifesaving interventions (Gombotz et al. 2006). Therefore, medical-surgical nurses play a pivotal role in assessing, recognizing, and intervening in a timely manner to secure fast, efficient, and effective resources and treatment for patients experiencing acute deterioration. Although nurses recognize the presence of physiological abnormalities indicating acute deterioration, nurses are reluctant to initiate basic life support interventions or activate rapid response teams (Considine $\&$ Botti 2004). Nurses' non-actions may be linked to fear of making wrong-decisions, initiating 
false alarms, or the desire to handle the situation in the early phase (Cioffi 2000a, Cioffi et al. 2006).

\section{LITERATURE REVIEW}

Early warning signs often precede acute deterioration events including cardiac arrest, unplanned admission to critical care, and unexpected death (Buist et al. 2004, Fuhrmann et al. 2008, Hillman et al. 2001, Kause et al. 2004), but patients with early warning signs are not always identified, and those who are identified are not always addressed in a timely manner (Hillman et al. 2005, Thompson et al. 2008). Failure to recognize and manage deterioration of a patient's condition in the early stages, such as changes in vital signs, is a common theme throughout the literature that leads to cardiac and respiratory arrest in hospitalized patients (Institute of Healthcare Improvement [IHI] 2012, Laurens \& Dwyer 2011). Multiple, complex, and overlapping factors have been identified as reasons that healthcare professionals fail to recognize and respond appropriately to acute patient deterioration. These factors include but are not limited to nurses' lack of knowledge and skills, inconsistent monitoring or detecting vital signs changes, delays in notifying medical staff of the signs of deterioration, failure to seek prompt assistance, failure to communicate with other staff, and lack of clarity about roles and responsibilities (Cioffi et al. 2006, Endacott et al. 2007, Hillman et al. 2001, National Patient Safety Agency 2007).

Organizational, cultural, and individual factors influence nurses' help-seeking behaviors during acute patient deterioration events. Several qualitative studies have explored nurses' experiences of decision-making, cue recognition, assessment, and communication during acute deterioration events (Cioffi 2000a, Cioffi et al. 2006, Minick \& Harvey 2003). Cioffi et al. (2006) and Cioffi (2000a) found that nurses felt uncertain about notifying the rapid response 
team (RRT) for fear of making a wrong decision and calling the RRT for a false alarm.

Additionally, nurses have a desire to deal initially with patient problems in the early stages resulting in delayed treatment. Furthermore, Cioffi et al. and Cioffi (2000a) found higher workload and complexity of the work environment decreased time for nurses to think about and analyze changes in vital signs resulting in delayed responses to deteriorating patients. Minick and Harvey (2003) found three themes describing ways of knowing that enable the early recognition of acute deterioration by medical-surgical nurses: knowing the patient directly, knowing the patient through family, and knowing something is not as expected. Cioffi (2000a) and Cioffi (2000b) identified four patient characteristics that nurses used when calling the RRT for “concerned about patient" criteria: feeling 'not right', color, agitation, and small or no changes in observations.

Cox et al. (2006) explored factors that influenced the experiences of nurses on general wards caring for critically ill patients. Five themes emerged from the data: clinical environment, professional relationships, patient assessment, nurses' feelings, and education needs. Reliance on machines and being distracted by other patients impacted nurses' abilities to assess deteriorating patients. In addition, professional relationships emerged as an important factor in obtaining help to support acute deteriorating patients. Feelings of panic and anxiety in handling acute deteriorating patients varied among nurses with varying levels of self-confidence that influenced their reactions or inactions. The importance of ongoing education was identified to assist with skill acquisition and knowledge of body system changes that would warrant nurses' immediate attention.

Endacott et al. (2007) found that nurses relied heavily on vital signs to identify patient deterioration, followed by changes in the patient's activity level. In addition, the researchers 
found that assessment practices by nurses were influenced by patient location, time of day, symptoms/condition of patient, and expertise of the nurse.

Very few quantitative studies have been conducted examining nurses' recognition and response to acute patient deterioration (Cooper et al. 2011, Murphy \& Fitzsimons 2004). Cooper et al. (2011) conducted a simulated study that examined rural nurses' abilities to assess and manage patient deterioration using measures of knowledge, situation awareness, and skill performance. The researchers found that knowledge levels varied in range from $27 \%$ to $91 \%$ with a mean score of $67 \%$, situation awareness and skill scores were low with nurses missing important observations and actions, and nurses did not use a systematic approach to patient assessment.

Murphy and Fitzsimons (2004) conducted an intervention study to determine the effectiveness of an immediate life support course (ILS) on the skill performance of nurses in future cardiac arrest events. The performance skills evaluated were the use of a defibrillator and inserting a laryngeal mask airway (LMA) during resuscitation. The authors found that nurses' confidence levels waned over time and that ILS training alone was not sufficient in improving nurses' skill performance over time.

Based on current research findings, further research is needed to explore medical-surgical nurses' perceived self-confidence and leadership abilities as first responders during acute patient deterioration events prior to the arrival of a RRT or a cardiac resuscitation team (CRT). In addition, further research is needed to understand medical-surgical nurses' experiences of handling patients in acute deterioration events. Knowledge gained from this study will provide strategies to assist nurses to be more knowledgeable, self-confident, and skilled in leadership abilities in caring for deteriorating patients. 


\section{PURPOSE}

The study purpose was to explore and understand medical-surgical nurses' perceived self-confidence and leadership abilities as first responders in recognizing and responding to patients experiencing acute deterioration prior to the arrival of a RRT or cardiac resuscitation team. The research questions were:

1) What are the perceived levels of self-confidence and leadership abilities of medicalsurgical nurses as first responders in acute patient deterioration events prior to the arrival of a RRT or CRT?

2) What is the relationship between medical-surgical nurses' demographic variables (age, years licensed, certification status, and highest nursing degree) and their perceived self-confidence and leadership abilities as first responders in acute patient deterioration events?

\section{THEORETICAL FRAMEWORK}

The theoretical framework for this study was Tanner's Clinical Judgment model (2006). The model offers a functional way in understanding the clinical reasoning and judgment of experienced nurses in a clinical setting, and is appropriate in describing their decision-making and actions in recognizing and responding to acute patient deterioration events. The model consists of four steps: noticing, interpreting, responding, and reflection. In the first stage of the clinical judgment process termed "noticing," nurses grasp the situation at hand. Noticing involves nurses making focused observations and obtaining information from the situation. This step requires nurses to use previous knowledge learned from other sources such as textbooks, assessment protocols, clinical practice guidelines, and previous clinical experiences in order to recognize change in patterns that exist within varying patient situations. During the 
“interpreting" step, nurses develop an understanding of the situation based on data collected, prioritize nursing actions to be taken, and develop an intervention plan to address the situation. The "responding" step involves nurses taking action and implementing their intervention plan. In order to respond appropriate, nurse must feel confident in using their clinical skills and leadership abilities to execute appropriate actions. The final step, "reflection," is the step where nurses reflect on actions taken and patients' responses to those actions and evaluate their choices and decisions. Through this evaluation process, nurses gain an understanding of varying situations and determine what works and does not work for application in future situations. By reflecting on the outcomes of various situations from actions taken, nurses develop a broader knowledge base and increased self-confidence in their leadership abilities to respond to future clinical situations.

\section{METHODS}

\section{Design}

A prospective, cross sectional, descriptive quantitative design using a survey method was used.

\section{Setting and Sample}

A convenience sample of nurses working in a five hospital, integrated healthcare system located in the southeast United States was recruited. Inclusion criteria included: a) a medical surgical nurse who provided direct patient care, b) willingness to complete the study questionnaires, and c) 18 years of age and older. With a power of .80 , an alpha value of .05 , and a small effect of .25 , a sample size of 126 participants was needed for the study. 


\section{Instruments}

A demographic questionnaire, self-confidence scale, and a leadership ability questionnaire comprised the study instruments. Permissions to use the instruments were obtained.

Self-confidence scale. The 12-item self-confidence scale (Hicks, 2006) measures selfconfidence in caring for patients in acute deterioration. Four dimensions are measured: a) accurately recognizing a change in patient's condition, b) performing basic physical assessments, c) identifying basic nursing interventions, and d) evaluating the effectiveness of interventions during acute deterioration. The items are rated on a Likert response scale ranging from 1 (not at all confident) to 5 (very confident), with higher scores indicating greater selfconfidence. Internal consistency reliability has been demonstrated by the instrument's author with Cronbach's alphas of 0.93 and 0.96 . The responses to all items on the questionnaire were summed for a total score for each participant.

Leadership ability questionnaire. The 8-item leadership ability questionnaire was derived from Gordon and Buckley's (2009) 14-item questionnaire that measures technical and non-technical skills of nurses responding to a crisis situation. For this study, only the nontechnical subscale items were used to measure nurses' leadership abilities during acute patient deterioration events. The items are rated on a Likert response scale ranging from 1 (not at all) to 4 (a great deal), with higher scores indicating greater perceived leadership abilities. Internal consistency reliability has been demonstrated by the instrument's author with Cronbach's alphas of 0.94 and 0.91 for the instrument. The responses to all items on the questionnaire were summed for a total score for each participant. 


\section{Protection of Human Subjects}

Prior to beginning data collection, approval for the study was obtained from the healthcare system's Nursing Research Committee and an Institutional Review Board (IRB). An informed consent was provided to each participant. Completion of the research questionnaires by participants was acknowledged as their consent to participate in the study.

\section{DATA COLLECTION PROCEDURE}

The research team recruited medical-surgical nurses by making rounds on nursing units and attending staff and shared governance meetings. Questionnaires were distributed to nurses face to face. The researchers reviewed in detail information about the study provided on the informed consent and answered questions to clarify any information. Participants were informed that they would be asked to complete three study questionnaires. Participants were informed that the questionnaires would take approximately 15 to 30 minutes to complete. Participants were also advised that questionnaires did not contain any identifying information linking the questionnaire to the participant and all information obtained was confidential. Completed questionnaires were returned directly to the researchers. Some participants were familiar with the researchers distributing and collecting the questionnaires while others were not.

\section{DATA ANALYSIS PLAN}

Quantitative data were analyzed with descriptive and inferential statistics using SPSS for Windows Release 18.0. Pre analysis data screening was conducted prior to statistical analysis. Descriptive statistics including frequencies, percentages, means, standard deviations and correlations were performed and reported on demographic variables, perceived self-confidence, and leadership ability scores. Inferential statistics, including regression analysis, were conducted to determine the relationship between independent variables (age, years licensed, certification 
status, and highest nursing degree) and perceived self-confidence and leadership ability scores. A $p$ value of $\leq .05$ was considered statistically significant.

\section{RESULTS}

\section{Sample}

From the 500 questionnaires distributed, 148 medical-surgical nurses completed questionnaires, representing a 29.6\% response rate (Table 1). The majority of nurses were female $(93.2 \%, n=138)$ and Caucasian $(70.8 \%, n=105)$. Nurses ranged in age from 22 to 63 years $(M$ $=40.8, S D=10.4)$ and over half $(65.4 \%, n=97)$ held baccalaureate degrees in nursing. Years practiced as a nurse ranged from 1 to 41 years with a mean of 13.8 years $(S D=10.8)$. Only a third $(32.4 \%, n=48)$ held a national certification. Most of the nurses worked full time $(96.6 \%, n$ $=143)$ during the day shift $(66.9 \%, n=99)$.

\section{Self-Confidence}

Self-confidence scores ranged from 33 to 60 with a mean of $52.38(S D=6.75)$, indicating that nurses felt very confident in handling APD events. Over half of the nurses felt very confident in recognizing signs and symptoms of a respiratory $(64.2 \%, n=95)$ or cardiac $(58.8 \%$, $n=87$ ) event (Table 2$)$. In contrast, only $33.1 \%(n=49)$ felt very confident in recognizing signs and symptoms of a neurological event, with $24.3 \%(n=36)$ not confident or somewhat confident. Less than three quarters of the nurses felt very confident in accurately assessing patients with shortness of breath $(60.8 \%, n=90)$, while just over half $(50.7 \%, n=75)$ felt very confident in accurately assessing patients with chest pain. Only 40.5\% $(n=60)$ felt very confident in their ability to accurately assess patients with a mental status change. Nurses felt more confident (very confident category) in evaluating the effectiveness of their interventions 
when responding to a patient with shortness of breath $(60.1 \%, n=89)$, compared to patients experiencing chest pain $(53.4 \%, n=79)$ or a change in mental status $(36.5 \%, n=54)$.

Reliability of the self-confidence scale was assessed resulting in a Cronbach's alpha reliability coefficient of .95 . The alpha score indicated a high degree of internal consistency.

\section{Leadership Ability}

Leadership ability scores ranged from 10 to 32 with a mean of $26.97(S D=5.12)$, indicating that nurses felt moderately comfortable in their leadership abilities during APD situations. Only $35.1 \%(n=52)$ were comfortable a great deal with being identified as a leader until the emergency team arrived with $19.6 \%(n=29)$ not at all or a little comfortable with being identified as a leader (Table 3). Less than half $(45.9 \%, n=68)$ of the nurses were comfortable a great deal in coordinating immediate responders from their unit. Only half $(52.0 \%, n=77)$ were comfortable a great deal in performing the handover procedure to the emergency team leader, while $55.4 \%(n=82)$ were comfortable a great deal in supporting the emergency team leader. Over half $(57.4 \%, n=85)$ felt comfortable a great deal with sharing information and keeping others informed during an emergency and voicing concerns to others during an emergency $(52.0 \%, n=77)$, while $62.8 \%(n=93)$ were comfortable a great deal with listening and responding to others' concerns during an emergency.

Reliability of the leadership ability questionnaire was assessed. Cronbach's alpha reliability coefficient was .94 . The alpha score indicated a high degree of internal consistency.

\section{Relationship between Perceived Self-Confidence and Leadership Abilities}

A Pearson's correlation coefficient was calculated for the relationship between participants' perceived self-confidence and leadership abilities. A moderate, positive correlation was found $(r(148)=.553, p<.001)$, indicating a significant linear relationship between the two 
variables. As perceived self-confidence increased, perceived leadership abilities in handling acute patient deterioration events increased.

\section{Regression}

To determine the multiple regression model with the best fit to predict participants' perceived self-confidence and leadership abilities based on their age, years licensed, highest nursing degree, and certification status (predictor variables), the researchers in consultation with a statistician, conducted 15 different regression models which included all possible combinations of the four predictor variables. Based on these analyses, age and certification status were identified as the best variables to predict participants' perceived self-confidence and leadership abilities. Both regression models were statistically significant (Table 4). The first overall model significantly predicted the dependent variable, self-confidence, $R^{2}=.08, R^{2}$ adj $=.07, F(2,139)$ $=5.948, p=.003$. This model accounted for $7 \%$ of the variance in the dependent variable, selfconfidence. Review of the $\beta$ weights specified that the two predictor variables, age, $\beta=.122, t$ $(139)=2.23, p=.027$ and certification status, $\beta=2.65, t(139)=2.20, p=.030$, significantly contributed to the model, with greater age and having a national certification predicting greater perceived self-confidence in managing as a first responder in an acute deterioration event.

The second overall model significantly predicted the dependent variable, leadership abilities, $R^{2}=.10, R^{2}$ adj $=.08, F(2,139)=7.406, p<.01$. This model accounted for $8 \%$ of the variance in the dependent variable, leadership ability. Review of the $\beta$ weights specified that the two predictor variables, age, $\beta=.108, t(139)=2.66, p=.009$ and certification status, $\beta=2.06, t$ $(139)=2.28, p=.024$, significantly contributed to the model, with greater age and having a national certification predicting greater perceived leadership ability in managing as a first responder in an acute deterioration event. 


\section{DISCUSSION}

In this research study we aimed to explore and understand medical-surgical nurses' perceived self-confidence and leadership abilities as first responders in recognizing and responding to patients experiencing acute deterioration prior to the arrival of a RRT or cardiac resuscitation team. The 148 participants were typical of nurses working within healthcare organizations in that the majority was female and Caucasian with varying years of work experiences (U. S. Department of Health and Human Services, Health Resources and Services Administration 2010). A significant, positive, moderate relationship was found between nurses' perceived self-confidence and leadership abilities in handling APD events. Nurses who are more self-confident in handling APD events felt more comfortable in executing leadership abilities during APD events. Failure to rescue, or inability to successfully intervene after complications have developed, affects cost and mortality/morbidity rates and has been determined to be the most frequently reported cause of preventable hospital deaths and intensive care unit (ICU) transfers (Hatler et al. 2009). Nurses who are more self-confident, execute leadership abilities, and use strong clinical reasoning skills may impact patient outcomes by identifying early warning signs of clinical deterioration and initiating early interventions to reduce failure to rescue events and patient mortality (Bobay et al. 2008, Brunt 2005, Clarke 2004).

Nurses in this study were more confident in recognizing, assessing, and evaluating the effectiveness of their interventions with patients experiencing respiratory and cardiac clinical deterioration, than patients experiencing neurological clinical deterioration. To our knowledge, this is the first study that has delineated between various patient types and nurses' perceived selfconfidence in handling patient deterioration events. This information is significant in aligning best practice strategies directed at nurses in handling a variety of acute patient deterioration 
events. Healthcare organizations routinely focus on respiratory and cardiac events by educating nurses on cardiopulmonary resuscitation but may neglect to educate nurses on other types of clinical deterioration. Andrews and Waterman (2005) stress the importance of educating nurses in the use of a systematic approach for conducting patient assessments and developing nurses' knowledge of pathophysiology associated with varying signs of clinical deterioration in order to enhance nurses' interpretation of assessment findings to improve patient outcomes.

In this study, age and certification status were found to influence nurses' perceived selfconfidence and leadership abilities in handling acute patient deterioration events. Increase in age and obtaining a national certification were associated with higher levels of perceived selfconfidence and leadership abilities. Interesting, only about $50 \%$ or less of nurses felt comfortable a great deal of the time in being identified as a leader, coordinating immediate responders from their unit, performing handover procedures to the emergency response team, supporting the emergency response team, sharing information and keeping others informed, and listening and responding to others' concerns during an emergency. These findings not only highlight the importance of experience and certification as important factors in developing clinical reasoning skills and self-confidence in nurses, but also identify the impact a lack of self-confidence and leadership skills may have on patient outcomes. Patients experiencing clinical deterioration require staff within a nursing unit to respond promptly and perform in a coordinated, efficient manner in order to provide the best opportunity for patient survival (Kilday et al. 2013). Nurses caring for patients must have self-confidence and leadership skills to direct other team members in resuscitation efforts within the first few minutes prior to the arrival of the RRT or cardiac resuscitation team as well as being a proficient and contributing team member to assist response teams throughout the resuscitation period. 


\section{LIMITATIONS}

Although the research study was carefully prepared there were some limitations. These limitations include the use of a convenience sample of nurses within one, five hospital integrated healthcare organization located in the southeast United States which may limit the ability to generalize the findings to other nurses and geographic locations. Using a convenience sample may introduce sampling bias; therefore caution is warranted when making inferences about the study findings. Future studies should focus on using random samples of nurses to further support the study findings. Additionally, nurses completed the questionnaires during work hours on their nursing units. This may have allowed nurses to interact with each other when completing the questionnaires.

Another limitation was the length of the questionnaires. This may have resulted in instrument fatigue for some nurses completing the questionnaires as well as being a deterrent to recruiting other nurses for the study.

The final limitation was an education intervention that occurred at one of the five hospitals. The rapid response team at one of the hospitals conducted education on acute signs of deterioration on medical-surgical nursing floors during the data collection phase. This may have influenced the response results on the questionnaires by nurses who obtained the training.

\section{CONCLUSIONS}

Although nurses felt very confident and comfortable with leadership abilities, there is a need for improvement to ensure nurses are competent in recognizing patients' deterioration cues and making sound decisions in taking appropriate, timely actions to rescue patients. Further strategies need to be developed to increase nurses' self-confidence and execution of leadership abilities in handling deterioration events for positive patient outcomes. Medical-surgical nurses 
are the front line defense in assessing and trending patient data for potential indicators of acute clinical deterioration and nurses must be knowledgeable and confident to be leaders in directing and initiating early interventions to improve patients' survival during APD events.

\section{RELEVANCE TO CLINICAL PRACTICE}

To ensure best outcomes for patients, healthcare organizations need to conduct baseline assessments of nurses to identify areas needing improvement in assessment skills, recognition, knowledge, leadership abilities, and self-confidence in clinical deterioration events on a routine basis. Fox (2007) stated that nurses should abide by the National Institute of Health and Care Excellence guideline (National Institute for Health \& Care Excellence [NICE] 2007) that recommends that all nurses have an adequate competency in assessing and recording physiological signs, interpreting physiological signs, and responding to abnormal physiological signs promptly and correctly. In order to achieve this level of accountability, the development of educational programs addressing various types of clinical deterioration scenarios such as the Acute Life-Threatening Events: Recognition and Treatment program (ALERT 2013), need to be implemented within healthcare organizations.

Additionally, team training using an evidence-based curriculum, TeamSTEPPs ${ }^{\circledR}$ (Team Strategies and Tools to Enhance Performance and Patient Safety) (Agency for Healthcare Research and Quality 2006), needs be implemented to optimize leadership abilities of medicalsurgical nurses prior to the arrival of the RRT or cardiac resuscitation team. Furthermore, team training is needed to enhance medical-surgical nurses' abilities to communicate effectively and optimize team performance when working with rapid response and cardiac resuscitation team members. During a clinical deterioration event, medical-surgical nurses are instrumental in 
conveying pertinent information leading up to the deterioration event that guides the emergency response team in differentiating causes of the event.

To promote optimal patient outcomes, nurses within healthcare organizations should be encouraged to obtain and maintain national certification to increase knowledge and clinical reasoning skills. Becoming nationally certified recognizes nurses' specialized knowledge, skills, and experience in meeting national standards in promoting optimal patient outcomes (American Board of Specialty Certification 2005). Although controversial, some research supports a link between certification status and improved patient outcomes (Coleman et al. 2009, KendallGallagher et al. 2011). 


\section{REFERENCES}

Agency for Healthcare Research and Quality. (2006). TeamSTEPPS instructor guide. AHRQ Publication No. 06-0020-0Rockville: Md.

ALERT. (2013). Acute life-threatening events: Recognition \& treatment. Retrieved from http://www.alert-course.com/course-information/

American Board of Specialty Nursing. (2005). A position statement on the value of nursing certification. Retrieved from http://nursingcertifcation.org/pdf/valve_ certification.pdf

Andrews, T. \& Waterman, H. (2005). Packaging a grounded theory of how to report physiological deterioration effectively. Journal of Advanced Nursing 52(5), 473-481.

Beaumont, K., Luettel, D., \& Thomson, R. (2008). Deterioration in hospital patients: early signs and appropriate actions. Nursing Standard, 23(1), 43-48.

Bobay, K., Fiorelli, K., \& Anderson, A. (2008). Failure to rescue: A primary study of patientlevel factors. Journal of Nursing Care Quality, 23(3), 211-212

Bright, D., Walker, W., \& Bion, J. (2004). Clinical review: Outreach-a strategy for improving the care of the acutely ill hospitalized patient. Critical Care, 8(1), 33-40.

Brunt, B. (2005). Models, measurements, and strategies in developing critical thinking skills. The Journal of Continuing Education, 36(6), 255-262.

Buist, M., Bernard, S., Nguyen, T., Moore, G., \& Anderson, J. (2004). Association between clinical abnormal observations and subsequent in-hospital mortality: A prospective study. Resuscitation, 62(2), 137-141. doi:10.1016/j.resuscitation.2004.03.005

Cioffi, J. (2000a). Nurses experiences of making decisions to call emergency assistance to their patients. Journal of Advanced Nursing, 32(1), 108-114. 
Cioffi, J. (2000b). Recognition of patients who require emergency assistance: a descriptive study. Heart \& Lung, 29(4), 262-268.

Cioffi, J., Salter, C., Wilkes, L., Vonu-Boriceanu, O., \& Scott, J. (2006). Clinicians' response to abnormal vital signs in an emergency department. Australian Critical Care, 19(2), 66-72.

Clarke, S. (2004). Failure to rescue. Lessons from missed opportunities in care. Nursing Inquiry, 11(2), 67-71.

Coleman, E. A., Coon, S. K., Lockhart, K., Kennedy, R. L., Montgomery, R., Copeland, N.,...Stewart, C. (2009). Effect of certification in oncology nursing on nursing-sensitive outcomes. Clinical Journal of Oncology Nursing, 13(2), 165-171.

Cohn, A. C., Wilson, W. M., Yan, B., Joshi, S. B., Heily, M., Morley, P., Maruff, L. E., ... Ajani, A. E. (2004). Analysis of clinical outcomes following in-hospital adult cardiac arrest. Internal Medical Journal, 34, 398-402.

Considine, J., \& Botti, M. (2004). Who, when, and where? Identification of patients at risk of an in-hospital adverse event: Implications for nursing practice. International Journal of Nursing Practice, 10(1), 21-31.

Cooper, S., McConnell-Henry, T., Cant, R., Porter, J., Missen, K., Kinsman, L., Endacott, R., \& Scholes, J. (2011). Managing deteriorating patients: Registered nurses’ performance in a simulated setting. The Open Nursing Journal, 5, 114-120.

Cox, H., James, J., \& Hunt, J. (2006). The experiences of trained nurses caring for critically ill patients within a general ward setting. Intensive \& Critical Care Nursing, 22(5), 283-293.

Endacott, R., Kidd, T., Chaboyer, W., \& Edington, J. (2007). Recognition and communication of patient deterioration in a regional hospital: A multi-methods study. Australian Critical Care, 20(3), 100-105. doi:10.1016/j.aucc.2007.05.002 
Fox, J. (2007). Safer care for acutely ill patients. British Journal of Nursing 16(15): 913.

Fuhrmann. L., Lippert, A., Perner, A., \& Ostergard, D. (2008). Incidence, staff awareness and mortality of patients at risk on general wards. Resuscitation, 77(3), 325-330.

Gombotz, H., Weh, B., Mitterndorfer, W., \& Rehak, P. (2006). In-hospital cardiac resuscitation outside the ICU by nursing staff equipped with automated external defibrillators-the first 500 cases. Resuscitation, 70(3), 416-422.

Gordon, C. J., \& Buckley, T. (2009). The effect of high-fidelity simulation training on medicalsurgical graduate nurses’ perceived ability to respond to patient clinical emergencies. Journal of Continuing Education in Nursing, 40(11), 491-500.

Hatler, C., Mast, D., Bedker, D., Johnson, R., Corderella, J., Torres, J.,... Plueger, M. (2009). Implementing a Rapid Response Team to Decrease Emergencies Outside the ICU: One Hospital's Experience. MEDSURG Nursing, 18(2), 84-126.

Hicks, F. D. (2006). Clinical decision-making self-confidence scale. In National Council of State Boards of Nursing. (2009). The effect of high-fidelity simulation on nursing students' knowledge and performance: A pilot study. Retrieved from https://www.ncsbn.org/09_SimulationStudy_Vol40_web_with_cover.pdf

Hillman, K. M., Bristow, P. J., Chey, T., Daffum, K., Jacques, T., Norman, S. L., Bishop, G. F., \& Simmons, G. (2001). Antecedents to hospital deaths. Internal Medicine Journal, 31(6), 343-348.

Hillman, K., Chen, J., Cretikos, M., Bellomo, R., Brown, D., Doig, G., Finfer, S., \& Flabouris, A. (2005). Introduction of the medical emergency team (MET) system: A clusterrandomized controlled trial. Lancet, 365(9477), 2091-2097. 
Institute for Healthcare Improvement (IHI). (2012). Establish a rapid response team. Retrieved from http://www.ihi.org/knowledge/Pages/Changes/EstablishaRapidResponseTeam.aspx.

Kause, J., Smith, G., Pyrtherch, D., Parr, M., Flabouris, A., \& Killman, K. (2004). A comparison of antecedents to cardiac arrests, deaths, and emergency intensive care admissions in Australia and New Zealand and the United Kingdom - the ACADEMIA study. Resuscitation, 62(3), 275-282.

Kendall-Gallagher, D., Aiken, L. H., Sloane, D. M., \& Cimiotti, J. P. (2011). Nursing specialty certification, inpatient mortality, and failure to rescue. Journal of Nursing Scholarship, 43(2), 188-194.

Kilday, D., Spiva, L., Barnett, J., Parker, C., Hart, P., 2012. The effectiveness of combined training modalities on neonatal rapid response teams. Clinical Simulation in Nursing, Published online March 28, 2012, e1-e8. doi:10.1016/j.ecns.2012.02.004.

Laurens, N., \& Dwyer, T. (2011). The impact of medical emergency teams on ICU admission rates, cardiopulmonary arrests and mortality in a regional hospital. Resuscitation, 82(6), 707-712. doi:10.1016/j.resuscitation.2010.11.031

Minick, P. \& Harvey, S. (2003). The early recognition of patient problems among medicalsurgical nurses. MedSurg Nursing: The Journal of Adult Health, 12(5), 291-297.

Murphy, M., \& Fitzsimons, D. (2004). Does attendance at an immediate life support course influence nurses' skill deployment during cardiac arrest? Resuscitation, 62(1), 49-54.

National Institute for Health and Clinical Excellence (2007). Acutely ill patients in hospital: Recognition of and response to acute illness in adults in hospital. Clinical Guideline 50. London: National Institute for Health and Clinical Excellence. Retrieved from http://publications.nice.org.uk/acutely-ill-patients-in-hospital-cg50 
National Patient Safety Agency. (2007). Recognizing and responding appropriately to early signs of deterioration in hospitalized patients. London: National Patient Safety Agency.

Peters, R., \& Boyde, M. (2007). Improving survival after in-hospital cardiac arrest: The Australian experience. American Journal of Critical Care, 16(3), 240-246.

Tanner. C. A. (2006). Thinking like a nurse: A research-based model of clinical judgment in nursing. Journal of Nursing Education, 45(6), 204-211.

Thompson, C., L. Dalgleish, T. Bucknall, C. Estabrooks, A. Hutchinson, K. Fraser, ... Saunders. (2008). The effects of time pressure and experience on nurses' risk assessment decisions: A signal detection analysis. Nursing Research, 57(5): 302-11.

U. S. Department of Health and Human Services, Health Resources and Services Administration (2010). The Registered Nurse Population: Findings from the 2008 National Sample Survey of Registered Nurses. Retrieved from http://bhpr.hrsa.gov/healthworkforce/rnsurveys/rnsurveyfinal.pdf 
Table 1

Demographic Characteristics of the Participants $(N=148)$

Characteristic

Age

Years Practiced

\begin{tabular}{lc}
$M$ & $S D$ \\
\hline 40.8 & 10.4 \\
13.8 & 10.8
\end{tabular}

Gender

Male

Female

10

138

6.8

93.2

Ethnicity/Race

White/Caucasian

Black/African American

Hispanic/Latino

Native American

Asian/Pacific Islander

Other

Missing

Degree

Diploma LPN

Diploma RN

Associate Degree

Baccalaureate Degree

Master's Degree

Employment Status

Fulltime

Part-time

PRN

Primary Shift

Day

Certification Status

No

Yes
70.8

17.6

2.7

1.4

5.4

.7

1.4

1.4

4.1

27.7

65.4

1.4

$143 \quad 96.6$

$3 \quad 2.0$

$2 \quad 1.4$

48 
ACUTE PATIENT DETERIORATION

Table 2

Percentages and Frequencies of Self Confidence Scale $(N=148)$

\begin{tabular}{|c|c|c|c|c|}
\hline Item & $\begin{array}{r}\text { Somewhat } \\
\text { Not } \\
\text { Confident }\end{array}$ & $\begin{array}{r}\text { Somewhat } \\
\text { Confident }\end{array}$ & $\begin{array}{r}\text { Moderately } \\
\text { Confident }\end{array}$ & $\begin{array}{r}\text { Very } \\
\text { Confident }\end{array}$ \\
\hline & $\%(n)$ & $\%(n)$ & $\%(n)$ & $\%(n)$ \\
\hline \multicolumn{5}{|l|}{ Recognition Signs/Symptoms } \\
\hline Cardiac arrest & $.7(1)$ & $7.4(11)$ & $33.1(49)$ & $58.8(87)$ \\
\hline Respiratory event & $.7(1)$ & $5.4(8)$ & $29.7(44)$ & $64.2(95)$ \\
\hline Neurological event & $5.4(8)$ & $18.9(28)$ & $42.6(63)$ & $33.1(49)$ \\
\hline \multicolumn{5}{|l|}{ Assessment } \\
\hline Chest pain & $2.0(3)$ & $11.5(17)$ & $35.1(52)$ & $51.4(76)$ \\
\hline Shortness of breath & $1.4(2)$ & $6.1(9)$ & $32.4(48)$ & $60.1(89)$ \\
\hline Mental status change & $1.4(2)$ & $13.5(20)$ & $43.9(65)$ & $41.2(61)$ \\
\hline \multicolumn{5}{|l|}{ Intervention } \\
\hline Chest pain & $1.4(2)$ & $12.8(19)$ & $31.1(46)$ & $54.7(81)$ \\
\hline Shortness of breath & $2.0(3)$ & $3.4(5)$ & $38.5(57)$ & $56.1(83)$ \\
\hline Mental status change & $3.4(5)$ & $20.2(30)$ & $39.9(59)$ & $36.5(54)$ \\
\hline \multicolumn{5}{|l|}{ Evaluate Effectiveness } \\
\hline Chest pain & $2.0(3)$ & $11.5(17)$ & $33.1(49)$ & $53.4(79)$ \\
\hline Shortness of breath & $1.4(2)$ & $8.1(12)$ & $30.4(45)$ & $60.1(89)$ \\
\hline Mental status change & $4.1(6)$ & $15.5(23)$ & $43.9(65)$ & $36.5(54)$ \\
\hline
\end{tabular}

* The category, "not at all confident" was not added to the table since nurses did not choose this category as a response on the questionnaires. 
ACUTE PATIENT DETERIORATION

Table 3

Percentages and Frequencies of Leadership Abilities Scale $(N=148)$

\begin{tabular}{lcccc}
\hline Item & Not At All & A Little & $\begin{array}{c}\text { To Some } \\
\text { Extent }\end{array}$ & $\begin{array}{c}\text { A Great } \\
\text { Deal }\end{array}$ \\
\hline & $\%(n)$ & $\%(n)$ & $\%(n)$ & $\%(n)$ \\
\cline { 2 - 5 } Be identified as a leader & $7.4(11)$ & $12.2(18)$ & $45.3(67)$ & $35.1(52)$ \\
Coordinate immediate responders & $2.0(3)$ & $14.3(21)$ & $37.8(56)$ & $45.9(68)$ \\
Perform handover to emergency team leader & $2.7(4)$ & $15.6(23)$ & $29.7(44)$ & $52.0(77)$ \\
Support emergency team leader & $2.0(3)$ & $12.2(18)$ & $30.4(45)$ & $55.4(82)$ \\
Share information \& keep others informed & $0.0(0)$ & $8.1(12)$ & $34.5(51)$ & $57.4(85)$ \\
Voice concerns to others & $2.0(3)$ & $9.5(14)$ & $36.5(54)$ & $52.0(77)$ \\
Listen and respond to others concerns & $1.4(2)$ & $5.4(8)$ & $30.4(45)$ & $62.8(93)$ \\
Utilize resources and external experts & $1.4(2)$ & $7.4(11)$ & $34.5(51)$ & $56.7(84)$ \\
\hline
\end{tabular}


ACUTE PATIENT DETERIORATION

\section{Table 4}

Multiple Regression for Variables Associated with Perceived Self-Confidence and Leadership Abilities $(N=148)$

\begin{tabular}{|c|c|c|c|c|c|c|}
\hline \multirow[b]{2}{*}{ Regression Variables } & \multicolumn{3}{|c|}{ Self-Confidence } & \multicolumn{3}{|c|}{ Leadership Ability } \\
\hline & B & SE B & $\beta$ & B & SE B & $\beta$ \\
\hline Age (in years) & .122 & .054 & $.186^{*}$ & .108 & .041 & $.219 * *$ \\
\hline Certification Status & 2.65 & 1.21 & $.183^{*}$ & 2.06 & .903 & $.188 *$ \\
\hline $\begin{array}{l}R^{2} \\
\text { Adjusted } R^{2} \\
F(p \text {-value for model })\end{array}$ & & $\begin{array}{c}.08 \\
.07 \\
8(p=.\end{array}$ & & & $\begin{array}{c}.10 \\
.08 \\
6(p=.\end{array}$ & \\
\hline
\end{tabular}

